\title{
Ranibizumab for choroidal neovascularization secondary to pseudoxanthoma elasticum: 4-year results from the PIXEL study in France
}

\author{
Gérard Mimoun $^{1}$ - Jean-Marc Ebran ${ }^{2} \cdot$ Typhaine Grenet $^{3,4}$ - Alain Donati $^{5}$. \\ Salomon-Yves Cohen ${ }^{4,6}$ • Anne Ponthieux ${ }^{7}$
}

Received: 21 April 2016/Revised: 13 March 2017 / Accepted: 24 April 2017 /Published online: 10 May 2017

(C) The Author(s) 2017. This article is an open access publication

\begin{abstract}
Purpose To evaluate the long-term effectiveness and safety of ranibizumab $0.5 \mathrm{mg}$ in patients with choroidal neovascularization $(\mathrm{CNV})$ secondary to pseudoxanthoma elasticum (PXE) in a real-world setting.

Methods A descriptive, observational, multicenter study in a retrospective and prospective cohort was conducted in France that included patients who had received at least one injection of ranibizumab $0.5 \mathrm{mg}$ during the period October 2011 to October 2014, for CNV secondary to PXE. Eligible patients were identified by review of medical records or during routine consultations. The main objectives were to describe patient characteristics, assess changes in best-corrected visual acuity [VA, Early Treatment Diabetic Retinopathy Study (ETDRS) letters] over time, the number and reasons for ranibizumab treatment and overall safety.

Results Of the 72 enrolled patients ( 98 eyes) from 23 centers, $39(54.2 \%)$ were male and mean [ \pm standard deviation (SD)] age was $59.6( \pm 8.3)$ years. The mean VA was 64.6 letters at the first ranibizumab injection, which was maintained at the 1year follow-up (64.7 letters). Thereafter, the mean VA was stable until the 4-year follow-up. At 4 years, the proportion
\end{abstract}

Anne Ponthieux

anne.ponthieux@novartis.com

Centre ophtalmologique de l'école militaire, Paris, France

2 University hospital of Angers, Angers, France

3 University hôpital of Avicenne, Bobigny, France

4 Ophthalmic Center of Laser and Medical Imaging, Paris, France

Ophthalmic center, Melun, France

6 University Hospital of Creteil, Creteil, France

7 Novartis Pharma S.A.S, Rueil-Malmaison, France of eyes with VA gain of $\geq 15$ letters was $3 / 19$ (15.8\%) and stable VA (change between -15 and +15 letters) was $10 / 19$ $(52.6 \%)$. Mean $( \pm \mathrm{SD})$ annual number of ranibizumab injections was $4.1( \pm 4.0)$, lower in the second versus first year. The most common reason for ranibizumab treatment was progression of neovascular activity (42.9\%). No deaths or new safety findings were reported.

Conclusions In patients with CNV secondary to PXE, ranibizumab $0.5 \mathrm{mg}$ resulted in stable VA over 4 years with a limited number of injections. Safety findings were consistent with the established safety profile of ranibizumab.

Keywords Angioid streaks · Choroidal neovascularization · Observational · Pseudoxanthoma elasticum $\cdot$ Ranibizumab

\section{Introduction}

Pseudoxanthoma elasticum (PXE) is a rare, predominantly autosomal recessive, systemic disorder caused by mutations in the adenosine triphosphate-binding cassette subtype $\mathrm{C}$ number 6 (ABCC6) gene [1, 2]. It primarily affects the skin, eyes, and cardiovascular system [2]. The underlying pathology of PXE involves progressive calcification and fragmentation of elastic fibers in the affected tissues [2]. The global prevalence of PXE is estimated to be approximately 1 in 25,000 to 150,000 [1-3]. PXE has a higher female preponderance and affects approximately twice as many females than males [4].

PXE manifests mainly in the posterior segment of the eye as reticular macular dystrophy, angioid streaks (AS), drusen of the optic nerve, peau d'orange, and comet-like peripheral lesions $[5,6]$. It is one of the most common causes of AS, accounting for $59 \%-87 \%$ of cases [7]. There is degeneration of the elastic fibers of the Bruch's membrane in PXE, which 
calcify and fragment to form breaks in the Bruch's membrane that are clinically evident as AS [8]. AS are asymptomatic in the earlier stages; however, in the later stages, they become symptomatic due to the development of choroidal neovascularization $(\mathrm{CNV})$ in the subretinal space $[1,2] . \mathrm{CNV}$ is the most severe complication of AS and develops in $72-86 \%$ of the eyes, more often bilaterally [7, 9-11]. If left untreated, it leads to central vision loss and legal blindness in over $50 \%$ of cases [1]. AS-associated CNV affects a relatively young and often active population, thus substantially affecting their quality of life [12].

Laser photocoagulation [13-15], verteporfin photodynamic therapy (vPDT) [16], and surgery $[17,18]$ have been explored in the past for treatment of CNV secondary to AS, albeit with little success due to the high rates of recurrence and progressive visual loss. Anti-vascular endothelial growth factor (VEGF) therapy has been used successfully for the treatment of CNV associated with age-related macular degeneration (AMD) $[19,20]$. Likewise, treatment with anti-VEGF agents such as bevacizumab (Avastin ${ }^{\circledR} ;$ Genentech/Roche) [21], and ranibizumab (Lucentis®; Genentech, South San Francisco, CA, USA; and Novartis Pharma AG, Basel, Switzerland) [22] has shown promise in CNV secondary to AS in several small studies with a short follow-up duration [23-28]; a recently published long-term retrospective study reinforces these short-term outcomes [29]. However, all these studies are in patients with AS-associated CNV in causes other than PXE. In AS-associated CNV secondary to PXE particularly, favorable visual outcomes over a long term with antiVEGF therapy has been reported in few case reports and smaller studies [12, 23, 24, 30-34].

To date, no medical treatment is approved for the treatment of CNV secondary to PXE. Results from short case series of one to nine patients with CNV secondary to PXE treated with ranibizumab have been encouraging [24, 30, 32-34]. However, data from large sample size over a long term are unavailable. In France, ranibizumab was granted temporary reimbursement from October 2011 to October 2014, for the treatment of patients with CNV secondary to PXE. In this context, the PIXEL study was conducted to evaluate the long-term effectiveness and safety of ranibizumab $0.5 \mathrm{mg}$ in patients with CNV secondary to PXE in a real-world setting.

\section{Methods}

\section{Study design}

PIXEL was a multicenter, descriptive, and observational study of a retrospective and prospective cohort conducted in realworld settings in France. Eligible patients were identified retrospectively by review of medical records or prospectively during routine consultations; the two methods were not mutually exclusive. A total of 5509 ophthalmologists across France were invited to participate to make the study as comprehensive as possible. The study protocol was designed to ensure inclusiveness by informing all French ophthalmologists regarding the study occurrence and requesting their participation through emails, letters, and phone calls. Patient participation was voluntary, and the ophthalmologists could prescribe treatment and follow-up with patients at their own discretion. The study was conducted in compliance with the Best Practices for Epidemiological Studies of April 2007. The study was approved by the Data Protection Advisory Committee and the National Commission on Informatics and Freedom. Informed consent was obtained from all individual participants included in the study.

\section{Patients}

Patients who had received at least one injection of ranibizumab $0.5 \mathrm{mg}$ in one eye since October 7, 2011 for CNV secondary to PXE and had provided signed informed consent (from legal guardians for minors) for participation were included in the study. Both eyes of a patient were included for analysis, if eligible. Administration of ranibizumab $0.5 \mathrm{mg}$ treatment to patients with CNV secondary to PXE was authorized by the French Health Authority between October 2011 and October 2014.

\section{Data collection}

Data were collected at different time points during routine treatment of the patients: at the time of diagnosis of CNV secondary to PXE, between diagnosis of $\mathrm{CNV}$ and the first ranibizumab injection, at the time of first ranibizumab injection, and during each routine visit after the first ranibizumab injection. A prospective follow-up visit was performed at 3, 6, 12 , and 18 months from the time of obtaining the informed consent. Patient enrollment, follow-up, and data collection were terminated in October 2014.

\section{Study objectives}

No primary objective was defined for the study. The objectives were as follows: (a) to describe demographic and clinical characteristics of the patients and eye(s), (b) to describe the functional and anatomical changes in the patients and eye(s) following ranibizumab treatment, (c) to assess the average annual number of ranibizumab injections, (d) to assess the reasons for re-administration, treatments other than ranibizumab, and reasons for their administration, (e) to assess the annual average number of patient follow-up visits, and (f) to assess safety and tolerability of ranibizumab. 


\section{Endpoints}

Functional and anatomical changes: The endpoints for assessing the functional changes included mean bestcorrected visual acuity [VA, Early Treatment Diabetic Retinopathy Study (ETDRS) letters] at each visit from the initiation of ranibizumab treatment and proportion of eyes with change in VA. The proportion of visually impaired patients was also evaluated according to the visual impairment definition of the World Health Organization (WHO): corrected VA between $\geq 20$ and $\leq 60$ ETDRS letters $(1 / 20$ and $3 / 10$ ) in the better eye. Visual loss was defined as the VA corrected to a range of $\geq 20$ and $\leq 65$ ETDRS letters in the better eye (i.e. $1 / 20$ and 4/10). Stable VA was defined as a change in VA between -15 and +15 ETDRS letters. The time to bilateral impairment was the duration between the first symptom in the eye/VA decline/diagnosis of new vessels/date of first ranibizumab injection (in the order of preference as indicated) in the first and the second eye impaired. The anatomical outcomes included proportion of eyes with change in $\mathrm{CNV}$, CNV leakage on fluorescein angiography, and retinal hemorrhages and change in central retinal thickness (CRT) over 4 years from the time of ranibizumab initiation. The stabilization or regression of $\mathrm{CNV}$ lesion was considered as disease remission.

Treatment exposure: The mean annual number of ranibizumab injections was calculated from the first injection as $365.25 \times$ number of ranibizumab injections/ (date of the last visit - date of the first injection). Similarly, the mean annual number of visits was calculated from the first ranibizumab injection as $365.25 \times$ number of consultations/(date of the last visit - date of the first ranibizumab injection). The follow-up duration was calculated from the first ranibizumab injection in the first ranibizumab-treated eye.

Safety and tolerability: The safety and tolerability were assessed by recording adverse events (AEs), non-serious and serious AEs occurring from the first injection of ranibizumab $0.5 \mathrm{mg}$ throughout the study period. AEs were coded as per the Medical Dictionary for Regulatory Activities (MedDRA) and were summarized as total number of AEs, proportion of patients with at least $1 \mathrm{AE}$ including at least $1 \mathrm{AE}$ by system organ class and preferred term as well.

\section{Statistical analyses}

All analyses were conducted on "patients" and "eyes" analyses populations. The patient analysis population comprised patients with ocular complications secondary to PXE who had received at least one injection of ranibizumab $0.5 \mathrm{mg}$ between October 7, 2011 and October 6, 2014 and had provided a signed informed consent form. For each patient, the first "affected" and the first "ranibizumab-treated" eyes were identified. The investigator reported the data from the first affected eye for the patient analysis population. A patient was considered to have a "bilateral" impairment if the pathology affected both the eyes (two affected eyes). The eyes analysis population comprised the ranibizumab-treated eyes from the patient analysis population. An eye was considered as treated if it had received at least one injection of ranibizumab between October 7, 2011 and October 6, 2014. The impaired eyes that were not treated with ranibizumab during the study inclusion period were excluded from the study. Therefore, in case of bilateral impairment, only the eye treated with ranibizumab was included in the study. The safety analysis population included the same number of patients as that in the patient analysis population.

The study objectives were purely descriptive. Descriptive analyses of the characteristics of all included patients were presented. The missing data were excluded while calculating the percentage for VA outcomes. Quantitative variables were described as mean, standard deviation (SD), median, and range, and qualitative variables in terms of absolute frequency and percentage by method.

The statistical analyses were performed using SAS software ${ }^{\circledR}$ version 9.2 .

\section{Results}

\section{Doctor participation, patient disposition, baseline demographics, and disease characteristics}

A total of 211 responses were received from the invited 5509 ophthalmologists, of which 70 (33.2\%) agreed to participate in the study. Of these, 23 (32.9\%) ophthalmologists from 23 centers enrolled at least one patient. The primary reason given for non-participation by $80.9 \%$ (114/141) of the ophthalmologists was lack of PXE patients, which was expected given the rarity of the disorder. Other reasons for non-participation by ophthalmologists included lack of time (7, 5.0\%), general non-participation in studies $(5,3.5 \%)$, lack of interest in the study $(3,2.1 \%)$, or "other" $(7,5.0 \%)$.

A total of 75 patients were enrolled in the study. Of the enrolled patients, three were excluded from the study. The reasons for exclusion of the patients were treatment outside of the study reference period in two patients and documented wrong injection during the evaluation period for one patient. Thus, a total of 72 patients were included in the patient analysis population. The mean follow-up duration was 39.2 $( \pm 27.3)$ months and the mean number of visits was 25.9 $( \pm 21.9)$.

A total of 150 eyes corresponding to the 75 patients were enrolled. Of these, $98(65.3 \%)$ eyes were treated with ranibizumab within the study reference period (October 2011-October 2014) and included in the eyes analysis population. The mean follow-up duration was $36.5( \pm 26.0)$ months. 
Thirteen eyes had retrospective follow-up data for 6 years, but due to their small numbers, the data were analyzed only for the first 4 years following the first injection of ranibizumab.

A majority of the patient analysis population was male (39; $54.2 \%)$, and the mean age was $59.6( \pm 8.3)$ years at the time of consent for participation in the study. The mean age of patients at the onset of first symptoms in the first impaired eye was $55.5( \pm 10.6)$ years. At the time of initiation of ranibizumab treatment, $47(65.3 \%)$ and $25(34.7 \%)$ patients had one and both eyes impaired, respectively. The median duration of the onset of symptoms between the two eyes was 2 years, and mean time to diagnosis of $\mathrm{CNV}$ between the two eyes was $2.4( \pm 3.0)$ years. The mean VA at the time of ranibizumab initiation in the first impaired eye and contralateral eye was $65.4( \pm 19.4)$ and $57.5( \pm 27.3)$, respectively.

All eyes for which study data were available $(N=69)$ underwent eye examinations. The most commonly performed examinations were fundus ophthalmoscopy (91.3\%), optical coherence tomography or fluorescein angiography (79.7\% for each of the tests), and color or monochromatic fundus photography (73.9\%). Autofluorescence and indocyanine green angiography were performed less frequently $(49.3 \%$ and $34.8 \%$, respectively). Approximately half of the patients $(32,44.4 \%)$ had nonocular complications secondary to PXE of which a majority $(27,84.4 \%)$ had skin complications. Data for skin biopsy were available for only $24(33.3 \%)$ patients at the time of diagnosis, of which two had a doubtful result and further information was missing for one. The remaining 21 $(87.5 \%)$ patients had positive results. The reasons for low numbers of biopsies could include the presence of a characteristic PXE lesion, easily identifiable by experienced dermatologists, not requiring confirmation by skin biopsy or avoidance of the procedure due to its invasive nature or complexities involved in interpreting results. A high proportion of eyes (77.6\%) had CNV, more frequently located juxtafoveally and subfoveally, at the initiation of ranibizumab treatment. At the time of diagnosis of ocular complications secondary to PXE, a high proportion of patients had ocular symptoms $(90.3 \%, 65)$ and AS $(91.7 \%$, 66 ) in the first ranibizumab-treated eye. Other ocular characteristics of the patients and eyes analyses populations are shown in Table 1.

\section{Efficacy}

\section{Bilateral impairment after initiation of ranibizumab $0.5 \mathrm{mg}$ (patient analysis population)}

Bilateral impairment of eyes was observed in 29 (40.3\%) patients at the time of the first ranibizumab injection and $38(52.8 \%)$ at the 1-year follow-up, $48(66.7 \%)$ each at the 2-year and the 4-year follow-up. The mean time between the first and the second eye to visual impairment and the onset of symptoms was $46.19( \pm 79.87)$ and 51.37 $( \pm 102.48)$ months, respectively.

\section{Functional changes after initiation of ranibizumab $0.5 \mathrm{mg}$ (eyes analysis population)}

The mean VA was 64.6 letters at the first ranibizumab injection, which was maintained at the 1-year follow-up (64.7 letters). Thereafter, VA remained stable until the 4-year follow-up (Fig. 1). The proportion of patients with a VA loss of $\geq 15$ ETDRS letters, VA gain of $\geq 15$ ETDRS letters or stable VA over 4 years is shown in Fig. 2. At the 4-year follow-up, 3/19 (15.8\%) patients showed a VA gain of $\geq 15$ letters and 10/19 (52.6\%) had a stable VA.

A total of 29 patients had VA impairment after the first ranibizumab injection over the entire follow-up duration. However, VA improved in five patients at the end of the follow-up. The proportion of visually impaired patients (per the WHO definition) increased over time from $4.8 \%(n=2)$ at 1 month to $21.7 \%(n=5)$ by the 4-year follow up after the first ranibizumab injection. One patient was considered blind (VA $<1 / 20$ in both eyes) after 6 years of the first ranibizumab injection with a VA of 5 ETDRS letters in the left eye and 15 ETDRS letters in the right eye. Another patient with visual impairment did not remain blind over the entire study duration as the VA improved to 20 ETDRS letters at the last evaluation.

\section{Anatomical changes after initiation of ranibizumab $0.5 \mathrm{mg}$ (eyes analysis population)}

The proportion of eyes with CNV decreased from $68.4 \%$ $(67 / 98)$ at the time of the first ranibizumab injection to $32.1 \%(9 / 28)$ at the 4-year follow-up (Fig. 3). CNV disappeared in $22.9 \%$ (11/48) of the eyes, 2 months following the first ranibizumab injection, and this proportion increased to one third at the 1-year $(33.3 \%, 24 / 72)$, 2year $(30.0 \%, 18 / 60)$, and 4-year $(32.1 \%, 9 / 28)$ followup. The proportion of eyes with presence of CNV leakage was $39.8 \%$ at the time of first injection and $14.3 \%$ at the 4-year follow-up. The proportion of eyes with retinal hemorrhages decreased from $26.5 \%$ at the first injection to $5.6 \%$ over 1 year, remained stable thereafter, and was $7.1 \%$ at the 4-year follow-up. Regardless of the time of evaluation, $95.9 \%, 74.5 \%$ and $60.2 \%$ of the eyes had $\mathrm{CNV}, \mathrm{CNV}$ leakage and retinal hemorrhages, respectively.

The mean CRT in the eyes analysis population initially decreased from $293.4( \pm 126.1) \mu \mathrm{m}$ at the time of the first ranibizumab injection to $247.1( \pm 49.7) \mu \mathrm{m}$ at the 6-month follow-up and was subsequently stable with a mean CRT of $247.4( \pm 59.0) \mu \mathrm{m}$ at the end of the 4-year follow-up. 
Table 1 Ocular characteristics (patients and eyes analyses populations) at the initiation of ranibizumab $0.5 \mathrm{mg}$ treatment

\begin{tabular}{|c|c|c|c|}
\hline \multirow[t]{2}{*}{ Characteristic $^{\mathrm{a}}$} & \multicolumn{2}{|c|}{ Patient analysis population $N=72$} & \multirow[t]{2}{*}{ Eyes analysis population $N=98$} \\
\hline & $\begin{array}{l}\text { First treated eye } \\
N=72\end{array}$ & $\begin{array}{l}\text { Contralateral eye } \\
N=72\end{array}$ & \\
\hline Angioid streaks, n (\%) & $66(91.7)$ & $56(77.8)$ & $73(74.5)$ \\
\hline CNV leakage, n (\%) & $51(70.8)$ & $21(29.2)$ & $50(51.0)$ \\
\hline Retinal hemorrhages, n (\%) & $34(47.2)$ & $10(13.9)$ & $33(33.7)$ \\
\hline $\mathrm{CNV}, \mathrm{n} \%$ & $64(88.9)$ & $30(41.7)$ & $76(77.6)$ \\
\hline Location & 64 & 30 & 76 \\
\hline Subfoveal & $24(37.5)$ & $12(40.0)$ & $25(32.9)$ \\
\hline Juxtafoveal & $23(35.9)$ & $8(26.7)$ & $28(36.8)$ \\
\hline Extrafoveal & $19(29.7)$ & $9(30.0)$ & $19(25.0)$ \\
\hline Unspecified & $3(4.7)$ & $5(16.7)$ & $5(6.6)$ \\
\hline VA (ETDRS letters), mean $( \pm \mathrm{SD})$ & $65.4( \pm 19.4)(n=54)$ & $57.5( \pm 27.3)(n=45)$ & - \\
\hline CRT $(\mu \mathrm{m})$, mean $( \pm \mathrm{SD})$ & $298.7( \pm 134.7)$ & $256.7( \pm 79.8)$ & $291.1( \pm 133.2)$ \\
\hline
\end{tabular}

${ }^{a}$ Patients with absent ocular characteristic and those with missing data are excluded

$C N V$, choroidal neovascularization; $C R T$, central retinal thickness; ETDRS, Early Treatment Diabetic Retinopathy Study; $S D$, standard deviation; VA, visual acuity

\section{Treatment exposure (eyes analysis population)}

Treatment with ranibizumab $0.5 \mathrm{mg}$ : The mean duration of ranibizumab treatment was $2.4( \pm 2.2)$ years. The mean duration between the first and the second ranibizumab injection was $114.8( \pm 204.4)$ days. The mean annual number of ranibizumab injections was $4.1( \pm 4.0) ; 4.1( \pm 2.3)$ in the first year and $2.7( \pm 2.3)$ in the second year. More than half of the eyes $(56.5 \%$ [52/92]) received the first three ranibizumab injections in 4 months, $47.9 \%(45 / 94)$ in 3 months, and $12.6 \%$ (12/95) in 2 months.

The most common reasons for initiating ranibizumab treatment (not exclusive) were progression of neovascular activity in $42.9 \%$ eyes and ocular complications of PXE in $40.8 \%$ eyes (Fig. 4). The most frequent reasons for retreatment with a second (58.2\%) and a third (51.2\%) injection were systematic treatment $(25.5 \%)$ as per the dosage recommendation of ranibizumab label, and $\mathrm{CNV}$ progression and signs of exudation (38.4\%) for the injections corresponding to the maintenance period.

Previous treatment Thirty-five (35.7\%) eyes had a history of previous treatment before ranibizumab initiation. Of these, $22(22.4 \%)$ had received treatment with antiVEGF other than ranibizumab, $17(17.3 \%)$ had received vPDT, nine $(9.2 \%)$ had received thermal laser photocoagulation, and five $(5.1 \%)$ had received corticosteroids. The mean number of previous treatments received was 8.4 $( \pm 9.2)$ with anti-VEGF other than ranibizumab, 2.7 $( \pm 3.0)$ with vPDT, $1.7( \pm 0.8)$ with thermal laser photocoagulation and $1.0( \pm 0.0)$ with corticosteroids.
Fig. 1 Mean VA at each visit from the time of first ranibizumab $0.5 \mathrm{mg}$ injection until 4 years (eyes analysis population) *After the first injection of ranibizumab $( \pm 1$ week for 1 and 2 months, \pm 2 weeks for 3 and 6 months, \pm 1 month for 9 months, and \pm 2 months for all other time points). ETDRS, early treatment diabetic retinopathy study; VA, visual acuity

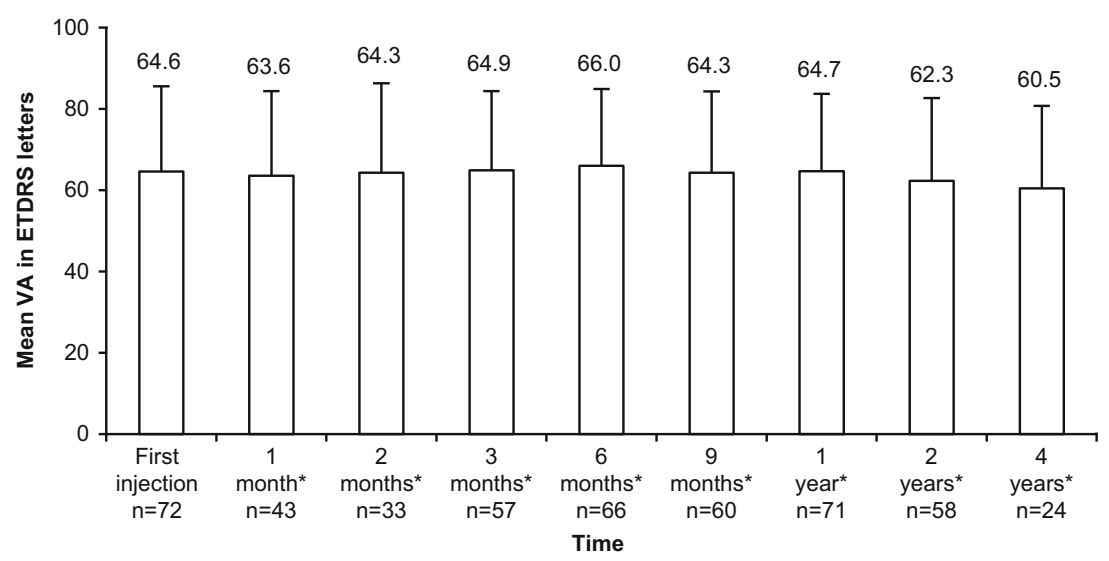


Fig. 2 Proportion of eyes with change in VA after initiation of ranibizumab $0.5 \mathrm{mg}$ treatment until 4 years (eyes analysis population) Stable VA, Change in VA between -15 and +15 ETDRS letters VA, visual acuity

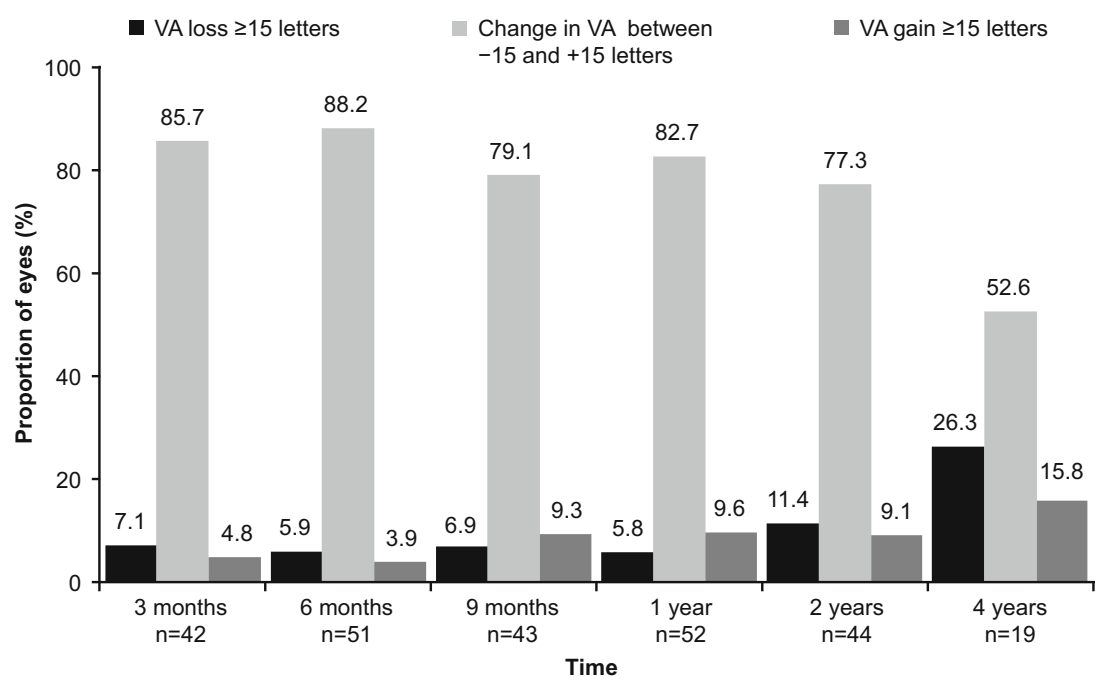

Concomitant treatment Thirteen eyes received concomitant treatment, with initial monthly injections of ranibizumab, to arrest $\mathrm{CNV}$ progression. Of the total 75 concomitant treatments administered, 68 were with anti-VEGF other than ranibizumab, three each were vPDT and corticosteroids, and one was thermal laser photocoagulation.

\section{Safety (safety analysis population)}

Overall, 24 AEs were reported in 14 (19.4\%) patients, of which 14 were ocular AEs reported in $10(13.9 \%)$ patients. The most frequent ocular AEs were ocular pain in three $(4.2 \%)$ patients and decrease in VA in two $(2.8 \%)$ patients. A total of 10 SAEs were reported in six (8.3\%) patients. A 50-year old female patient, with a history of dyslipidemia, hypertension since 2011 and bilateral carpal tunnel syndrome and a family history of dyslipidemia, hypertension, type 2 diabetes and arterial hypertension, was hospitalized for cerebral ischemic infarction, suspected to be related to ranibizumab treatment. Magnetic resonance imaging (MRI) of the brain confirmed the presence of an ischemic infarct in the left pontine region. Before the event, she had received 17 injections of anti-VEGF agents (including 15 ranibizumab injections) and 11 injections of anti-VEGF agents (including nine ranibizumab injections) in the left and right eye, respectively. She was receiving concomitant treatment with rosuvastatin, telmisartan, acetylsalicylate lysine, candesartan, hydrochlorothiazide, and cholecalciferol. Following her recovery 1 week later, the patient restarted ranibizumab treatment and received nine injections of ranibizumab. Another patient, a 53-year old male, was hospitalized following a transient ischemic attack, which was considered not related to ranibizumab by the investigator. An ultrasound of the supra-aortic trunks and transcranial Doppler showed stage III stenosis of the end of the left internal carotid artery and occlusion of the right vertebral artery. A transesophageal and transthoracic echocardiogram showed a bicuspid aortic valve and dilatation of the thoracic aorta $(52 \mathrm{~mm})$. MRI of the brain revealed ischemia of
Fig. 3 Proportion of eyes with choroidal neovascularization at each visit from the time of first ranibizumab $0.5 \mathrm{mg}$ injection until 4 years (eyes analysis population) *After the first injection of ranibizumab $( \pm$ 1 week for 1 and 2 months, \pm 2 weeks for 3 and 6 months, \pm 1 month for 9 months, and \pm 2 months for all other time points)

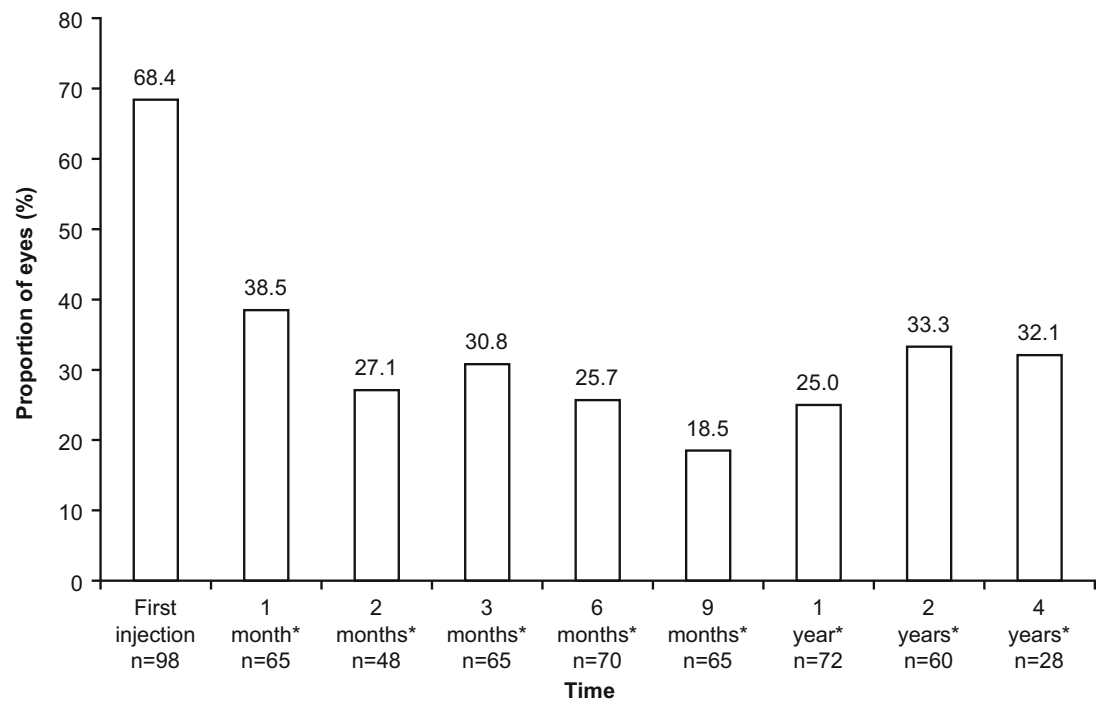


Fig. 4 Reasons for initiating treatment with ranibizumab $0.5 \mathrm{mg}$ (eyes analysis population) PXE, pseudoxanthoma elasticum; VA, visual acuity

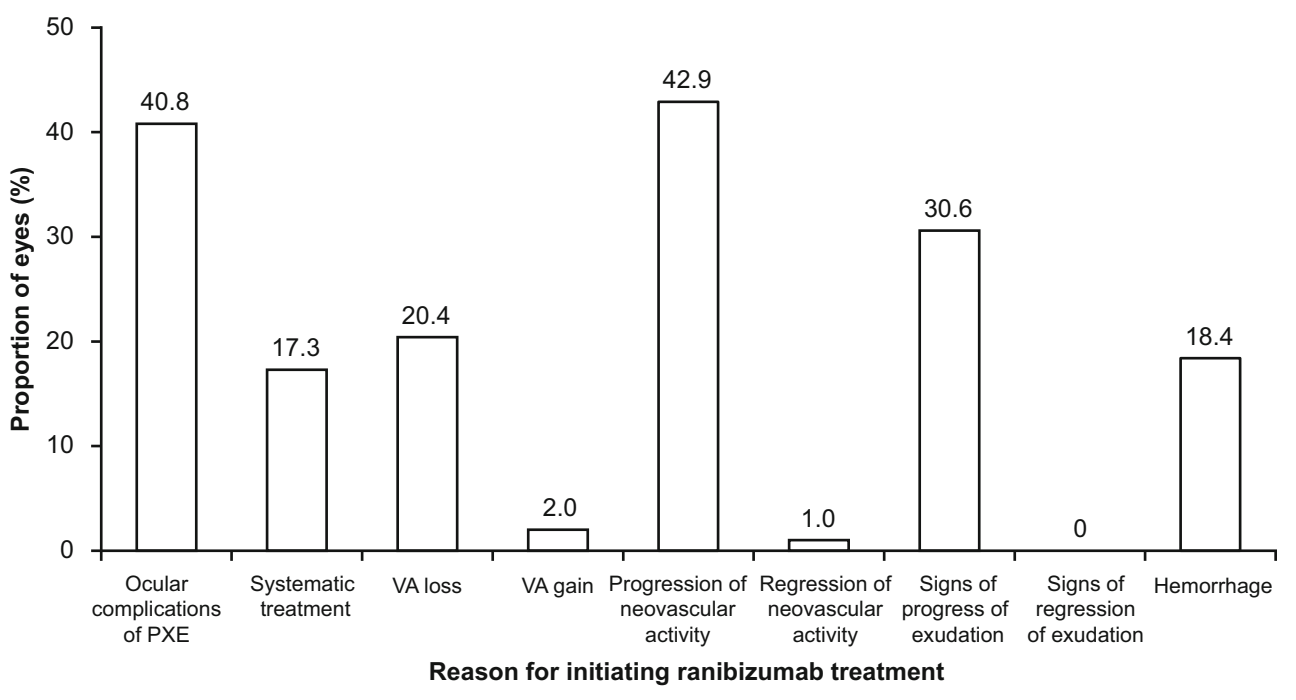

the left lenticular nucleus. Arterial thromboembolic events pose a theoretical risk to patients receiving anti-VEGF therapy and were monitored as part of the ranibizumab risk management program. One SAE of endophthalmitis was suspected to be related to intravitreal injection technology. No death was reported in the study. The overall safety summary is presented in Table 2 .

\section{Discussion}

CNV is the most severe ocular complication of PXE [9]. Untreated cases of CNV secondary to PXE progress to central blindness and thus have a poor prognosis [1, 14]. Findings from the PIXEL study, conducted in a real-world setting, showed that the mean VA was maintained at 1-year with ranibizumab $0.5 \mathrm{mg}$ treatment and thereafter, it remained stable until 4-year follow up. The CNV lesions regressed or stabilized with a limited number of ranibizumab $0.5 \mathrm{mg}$ injections. The proportion of eyes with CNV, $\mathrm{CNV}$ leakage and retinal hemorrhage reduced compared with that at the initiation of ranibizumab treatment. The proportion of eyes with $\mathrm{CNV}$ was reduced to more than half at 4 years, while those with retinal hemorrhage was reduced to nearly a quarter by 2 years and then remained stable up to 4 years. The proportion of patients with CNV leakage was reduced to less than half at the 4-year follow-up. Ranibizumab $0.5 \mathrm{mg}$ was also well tolerated and showed a favorable safety profile with no reported deaths.

In the PIXEL study, the average age of patients at the appearance of first symptoms was 55.5 years, which is consistent with that in previous literature [23, 24, 29, 31]. The average time to bilateralization of CNV between the two eyes was reported as 2.4 years in the PIXEL study, which was comparable to that reported previously (1.5 years) [9].

Although AS-associated CNV can develop secondary to many systemic disorders, PXE is the most common cause [7]. Since PXE is a rare disorder, much of the experience for the treatment of AS-associated $\mathrm{CNV}$ emerges from causes other than PXE. Published literature on anti-VEGF treatment for CNV secondary to AS, mainly case series or studies with either a small sample size or short follow-up, report VA gain or stabilization in 85-93\% of the study population [25-28]. Tilleul et al. reported long-term effectiveness of ranibizumab in the largest series (35 eyes of 27 patients) with ASassociated CNV of which $40.7 \%$ was due to PXE [29]. Stabilization and improvement of VA was noted in $62.9 \%$ of 35 eyes ( 27 patients) over 4 years. The 2-year results from the same study had reported VA stabilization and gain in $85.7 \%$ patients [26]. The VA stabilization and gain was limited to $60 \%$ in patients with PXE. Results from the PIXEL study are similar to that from the aforementioned study [26, 29], at the 2-year and 4-year follow-ups $(86.3 \%$ and $68.4 \%$, respectively), for VA gain and stabilization in PXE patients with ASassociated CNV. Tilleul et al. had also concluded from their 4year-results that it was easy to achieve but difficult to maintain stable VA over the long term with ranibizumab in ASassociated CNV in eyes with higher initial VA [29]. In the PIXEL study, $50 \%$ of the patients had received prior treatment, of which $29.2 \%$ had received treatment with other anti-VEGF agents. Thus, one-third of the patients were possibly non-responders to anti-VEGFs which could have hindered VA gain over time.

Anatomically, the presence of $\mathrm{CNV}$ and $\mathrm{CNV}$ leakage assessed by fluorescein angiography decreased during treatment with ranibizumab from the time of first injection through follow-up after 1, 2, and 4 years. The proportion of eyes with $\mathrm{CNV}$ at first injection was $68.4 \%$ and dropped by more than half at 1-year follow-up (25.0\%) and then remained relatively stable at 2 and 4 years of follow-up $(33.3 \%$ and $32.1 \%$, respectively). The most common reason for retreatment was systematic treatment as per the ranibizumab dosage recommendation $(25.5 \%)$ and not CNV progression (9.6\%). Thus, it can be assumed that the average number of injections needed for control of CNV would actually be less than what was 
Table 2 Overall safety summary (safety analysis population)

\begin{tabular}{|c|c|c|}
\hline Safety parameter & $\begin{array}{l}\text { Patients, } \\
N=72 \\
\mathrm{n}(\%)\end{array}$ & $\mathrm{AEs}^{\mathrm{a}}$ \\
\hline Total AEs & $14(19.4)$ & 24 \\
\hline \multicolumn{3}{|l|}{ Ocular AEs } \\
\hline Eye pain & $3(4.2)$ & 3 \\
\hline Visual acuity decrease & $2(2.8)$ & 2 \\
\hline Amaurosis & $1(1.4)$ & 1 \\
\hline Cataract & $1(1.4)$ & 1 \\
\hline Conjunctival hemorrhage & $1(1.4)$ & 1 \\
\hline Eye irritation & $1(1.4)$ & 1 \\
\hline Eyelid oedema & $1(1.4)$ & 1 \\
\hline Macular oedema & $1(1.4)$ & 1 \\
\hline Retinal vascular disorder & $1(1.4)$ & 1 \\
\hline Blurred vision & $1(1.4)$ & 1 \\
\hline Vitreous detachment & $1(1.4)$ & 1 \\
\hline \multicolumn{3}{|l|}{ Nervous system disorders } \\
\hline Carotid stenosis & $1(1.4)$ & 1 \\
\hline Ischemic cerebral infarction & $1(1.4)$ & 1 \\
\hline Sciatica & $1(1.4)$ & 1 \\
\hline Transient ischemic attack & $1(1.4)$ & 1 \\
\hline Occlusion of the vertebral artery & $1(1.4)$ & 1 \\
\hline Infections and infestations & $2(2.8)$ & 2 \\
\hline Congenital, familial and genetic disorders & $1(1.4)$ & 1 \\
\hline \multicolumn{3}{|l|}{ Injury, poisoning, and complications linked } \\
\hline Vascular disorders & $1(1.4)$ & 1 \\
\hline \multirow{3}{*}{$\begin{array}{l}\text { Ocular AEs suspected to } \\
\text { Eye pain } \\
\text { Blurred vision }\end{array}$} & $1(1.4)$ & 2 \\
\hline & $1(1.4)$ & 1 \\
\hline & $1(1.4)$ & 1 \\
\hline \multirow{2}{*}{$\begin{array}{l}\text { Non-ocular AEs suspected to be drug-related } \\
\text { Ischemic cerebral infarction }\end{array}$} & $1(1.4)$ & 1 \\
\hline & $1(1.4)$ & 1 \\
\hline Total SAEs & $6(8.3)$ & 10 \\
\hline
\end{tabular}

${ }^{a}$ Described as number of events. The percentages are calculated with respect to $\mathrm{N}$ (number of patients)

$A E s$, adverse events; $n$, number of patients with at least one $\mathrm{AE}$

observed in the study as the proportion of eyes with CNV improved at subsequent follow-up visits, highlighting the decreased rate of $\mathrm{CNV}$ progression. In addition, the presence of CNV leakage, one of the markers of disease severity, decreased from $39.8 \%$ at the first injection to $8.3 \%$ at 1 year, $18.3 \%$ at 2 years, and $14.3 \%$ at 4 years. However, due to the observational nature of the study design, not all patients underwent a fluorescein angiography during their follow-up. Therefore, one should be cautious when interpreting these data as CNV leakage may have been underestimated. In the future, for long-term serial monitoring of CNV activity in patients with PXE, optical coherence tomography angiography (OCT-A) could be a valuable non-invasive tool. OCT-A also holds enormous potential in early detection of CNV [35]. Earlier experience with anti-VEGF treatment in PXE patients supports initiation of treatment early in the disease pathology as it may potentially arrest disease progression at the outset and optimize treatment outcomes [31]. Thus, OCT-A can help in optimizing treatment outcomes by early detection of $\mathrm{CNV}$ and monitoring recurrences as well as existing lesions.

In this study, the mean CRT was observed to decrease from the time of the first ranibizumab injection until 6 months, and thereafter remained stable until the 4-year-follow up. Smaller studies $[12,24,31]$ in patients with CNV secondary to PXE have also reported reduction in CRT with anti-VEGF (including ranibizumab) treatment. In addition, Tilleul et al. reported stabilization or decrease in macular thickness in almost $50 \%$ of the patients receiving ranibizumab treatment for CNV secondary to AS due to different causes including PXE [29].

Ranibizumab is a humanized monoclonal antibody Fab fragment that is designed specifically for ocular use and is approved for the treatment of CNV secondary to AMD [22]. However, off-label use of bevacizumab to treat $\mathrm{CNV}$ is quite common in clinical practice. Bhatnagar et al. reported shortterm success in stabilizing or improving VA with bevacizumab in PXE patients with AS-associated CNV, but in 50\% of patients there was a need for serial repeated injections (mean number of injections: 1.8) within a short span of 6 months [23]. Finger et al. explored bevacizumab treatment in 16 eyes with CNV secondary to PXE for 28 months and reported improved functional and anatomical outcomes with a mean of 6.5 injections over 28 months [31]. In the PIXEL study, VA stabilization was achieved over 4 years with an average of 4.1 injections, which was much lower compared with the above study. The incidence of ocular/nonocular AEs was low and consistent with that observed in the previously reported clinical studies of ranibizumab in patients with nAMD [19, 20,36-38]. Only one case of cerebral ischemic infarction was suspected to be related to ranibizumab treatment.

To our knowledge, PIXEL is the first study to report the effectiveness and safety of ranibizumab $0.5 \mathrm{mg}$ treatment in a large series of patients with CNV secondary to PXE for a long follow-up duration of 4 years. Despite the rarity of the condition, the study had a robust sample size of 98 eyes from 72 patients. However, we acknowledge that this study had some limitations: the observational design and the real world settings of the study are limitations as data from all patients were not available at each time point; combining retrospective and prospective data imply some flaws even if the study was designed in a manner to both enlarge the study population and obtain long-term real-world data in a rare disease for which no medical treatment is currently approved and long-term data remains unavailable, and the variations in treatment protocols, ocular examinations in this multicenter study, and patient attrition over the 4-year follow-up period add to the study limitations. Indeed, instruments for diagnosis may have differed across the centers and the number of eyes available for observation was much lower at the 4-year follow-up; therefore, results should be interpreted cautiously ( $N=98$ eyes at first injection, $N=79$ eyes at 1 -year followup, $N=57$ eyes at 2 years of follow-up, and $N=28$ eyes at 4 years of follow-up). Another important limitation of this study 
is the absence of assessment of macular atrophy that can develop in PXE independent of CNV, resulting in severe vision loss. Finally, the patients were treated at the investigator's discretion, thus drawing a conclusion on the dosing regimen of ranibizumab is beyond the scope of the study. Comparison across various studies should be done with caution as the study populations vary with respect to study settings, dosing regimens, previous treatment profiles and underlying comorbidities.

In conclusion, the PIXEL study indicated that treatment with ranibizumab $0.5 \mathrm{mg}$ under real-world setting results in stable VA up to 4 years and regression/stabilization of lesions with a limited number of injections in patients with CNV secondary to PXE. Considering the rarity of PXE and the fact that there is no established treatment for this disorder, treatment with ranibizumab offers a promising therapeutic option for patients with CNV secondary to PXE. Further prospective, longer term studies are needed to evaluate the long-term effectiveness and safety of this treatment.

Acknowledgements The study was sponsored by Novartis Pharma S.A.S, Rueil-Malmaison, France. The authors thank Deepali Garg from Medical Communications, Novartis Healthcare Private Ltd., Hyderabad, India for her medical writing and editorial support towards the development of this manuscript and Najeeb Ashraf for editorial and submission assistance for the manuscript.

\section{Compliance with ethical standards}

Funding Novartis Pharma SAS provided financial support in the form of study funding.

The sponsor had no role in the design or conduct of this research.

Conflict of interest The authors had the following financial disclosures: Gérard Mimoun: No disclosures. Jean-Marc Ebran: Consultant for Novartis and Bayer. Typhaine Grenet: Consultant for Novartis, Bayer, and Allergan. Alain Donati: consultant for Novartis and Bayer. Salomon-Yves Cohen: Consultant for Novartis Pharma SAS, Bayer, Alcon, Allergan, and Thea. Anne Ponthieux: Employee of Novartis Pharma S.A.S, Rueil-Malmaison, France.

All authors certify that they have no affiliations with or involvement in any organization or entity with any non-financial interest (such as personal or professional relationships, affiliations, knowledge or beliefs) in the subject matter or materials discussed in this manuscript.

Ethical approval All procedures performed in studies involving human participants were in accordance with the ethical standards of the institutional and/or national research committee and with the 1964 Helsinki declaration and its later amendments or comparable ethical standards.

For this type of study formal consent is not required.

Informed consent Informed consent was obtained from all individual participants included in the study.

Open Access This article is distributed under the terms of the Creative Commons Attribution 4.0 International License (http:// creativecommons.org/licenses/by/4.0/), which permits unrestricted use, distribution, and reproduction in any medium, provided you give appropriate credit to the original author(s) and the source, provide a link to the Creative Commons license, and indicate if changes were made.

\section{References}

1. Chassaing N, Martin L, Calvas P, Le Bert M, Hovnanian A (2005) Pseudoxanthoma elasticum: a clinical, pathophysiological and genetic update including 11 novel ABCC6 mutations. J Med Genet 42:881-892. doi:10.1136/jmg.2004.030171

2. Finger RP, Charbel Issa P, Ladewig MS, Gotting C, Szliska C, Scholl HP, Holz FG (2009) Pseudoxanthoma elasticum: genetics, clinical manifestations and therapeutic approaches. Surv Ophthalmol 54:272-285. doi:10.1016/j.survophthal.2008.12.006

3. Uitto J, Jiang Q, Varadi A, Bercovitch LG, Terry SF (2014) Pseudoxanthoma Elasticum: diagnostic features, classification, and treatment options. Expert Opin Orphan Drugs 2:567-577

4. Bercovitch L, Terry P (2004) Pseudoxanthoma elasticum 2004. J Am Acad Dermatol 51:S13-S14. doi:10.1016/j.jaad.2004.01.015

5. Gass JD (1997) Angioid streaks. In. Stereoscopic Atlas of Macular Diseases St Louis: Mosby: 118-125

6. Gass JD (2003) “comet” lesion: an ocular sign of pseudoxanthoma elasticum. Retina 23:729-730

7. Connor PJ Jr, Juergens JL, Perry HO, Hollenhorst RW, Edwards JE (1961) Pseudoxanthoma elasticum and angioid streaks. A review of 106 cases. Am J Med 30:537-543

8. Baccarani-Contri M, Vincenzi D, Cicchetti F, Mori G, PasqualiRonchetti I (1994) Immunochemical identification of abnormal constituents in the dermis of pseudoxanthoma elasticum patients. Eur J Histochem: EJH 38:111-123

9. Georgalas I, Papaconstantinou D, Koutsandrea C, Kalantzis G, Karagiannis D, Georgopoulos G, Ladas I (2009) Angioid streaks, clinical course, complications, and current therapeutic management. Ther Clin Risk Manag 5:81-89

10. Clarkson JG, Altman RD (1982) Angioid streaks. Surv Ophthalmol 26:235-246

11. Mansour AM, Shields JA, Annesley WH Jr, El-Baba F, Tasman W, Tomer TL (1988) Macular degeneration in angioid streaks. Ophthalmol J Int Ophtalmol Int J Ophthalmol Zeitschrift Augenheilkund 197:36-41

12. Myung JS, Bhatnagar P, Spaide RF, Klancnik JM Jr, Cooney MJ, Yannuzzi LA, Freund KB (2010) Long-term outcomes of intravitreal antivascular endothelial growth factor therapy for the management of choroidal neovascularization in pseudoxanthoma elasticum. Retina 30: 748-755. doi:10.1097/IAE.0b013e3181c596b1

13. Lim J, Bressler NM, Marsh MJ, Bressler SB (1993) Laser treatment of choroidal neovascularization in patients with angioid streaks. Am J Ophthalmol 116:414-423

14. Pece A, Avanza P, Galli L, Brancato R (1997)Laser photocoagulation of choroidal neovascularization in angioid streaks. Retina 17:12-16

15. Browning AC, Chung AK, Ghanchi F, Harding SP, Musadiq M, Talks SJ, Yang YC, Amoaku WM, United Kingdom PDTUG (2005) Verteporfin photodynamic therapy of choroidal neovascularization in angioid streaks: one-year results of a prospective case series. Ophthalmology 112:1227-1231. doi:10.1016/j.ophtha.2005.02.011

16. Aras C, Baserer T, Yolar M, Yetik H, Artunay O, Guzel H, Ozkan S (2004) Two cases of choroidal neovascularization treated with transpupillary thermotherapy in angioid streaks. Retina 24:801-803

17. Roth DB, Estafanous M, Lewis H (2001) Macular translocation for subfoveal choroidal neovascularization in angioid streaks. Am J Ophthalmol 131:390-392

18. Adelberg DA, Del Priore LV, Kaplan HJ (1995) Surgery for subfoveal membranes in myopia, angioid streaks, and other disorders. Retina 15:198-205

19. Rosenfeld PJ, Brown DM, Heier JS, Boyer DS, Kaiser PK, Chung CY, Kim RY, Group MS (2006) Ranibizumab for neovascular agerelated macular degeneration. N Engl J Med 355:1419-1431. doi: 10.1056/NEJMoa054481 
20. Brown DM, Michels M, Kaiser PK, Heier JS, Sy JP, Ianchulev T, Group AS (2009) Ranibizumab versus verteporfin photodynamic therapy for neovascular age-related macular degeneration: two-year results of the ANCHOR study. Ophthalmology 116:57-65 e55. doi: 10.1016/j.ophtha.2008.10.018

21. AVASTIN Prescribing Information. http://www.accessdata.fda.gov/ drugsatfda_docs/label/2009/125085s0169lbl.pdf. accessed 12 Feb 2016

22. Lucentis ${ }^{\circledR}$ Summary of Product Characteristics. Basel, Switzerland: Novartis AG; 2013. http://www.ema.europa.eu/docs/ en_GB/document_library/EPAR_Product_Information/human/ 000715/WC500043546.pdf. accessed 12 Feb 2016

23. Bhatnagar P, Freund KB, Spaide RF, Klancnik JM Jr, Cooney MJ, Ho I, Fine HF, Yannuzzi LA (2007) Intravitreal bevacizumab for the management of choroidal neovascularization in pseudoxanthoma elasticum. Retina 27:897-902. doi:10.1097/IAE. 0b013e31809ff5df

24. Finger RP, Charbel Issa P, Hendig D, Scholl HP, Holz FG (2011) Monthly ranibizumab for choroidal neovascularizations secondary to angioid streaks in pseudoxanthoma elasticum: a one-year prospective study. Am J Ophthalmol 152:695-703. doi:10.1016/j.ajo. 2011.03.022

25. Ladas ID, Kotsolis AI, Ladas DS, Niskopoulou M, Georgalas I, Papakonstantinou D, Rouvas AA (2010) Intravitreal ranibizumab treatment of macular choroidal neovascularization secondary to angioid streaks: one-year results of a prospective study. Retina 30: 1185-1189. doi:10.1097/IAE.0b013e3181d2f11d

26. Mimoun G, Tilleul J, Leys A, Coscas G, Soubrane G, Souied EH (2010) Intravitreal ranibizumab for choroidal neovascularization in angioid streaks. Am J Ophthalmol 150:692-700 e691. doi:10.1016/ j.ajo.2010.06.004

27. Shah M, Amoaku WM (2012) Intravitreal ranibizumab for the treatment of choroidal neovascularisation secondary to angioid streaks. Eye 26:1194-1198. doi:10.1038/eye.2012.116

28. Vadala M, Pece A, Cipolla S, Monteleone C, Ricci F, Boscia F, Cillino S (2010) Angioid streak-related choroidal neovascularization treated by intravitreal ranibizumab. Retina 30:903-907. doi:10. 1097/IAE.0b013e3181cafc75

29. Tilleul J, Mimoun G, Querques G, Puche N, Zerbib J, Lalloum F, Srour M, Souied EH (2015) Intravitreal ranibizumab for choroidal neovascularization in angioid streaks: four-year follow-up. Retina 36:483-491. doi:10.1097/IAE.0000000000000745

30. Derriman L, Marshall J, Moorman C, Downes SM (2008) The use of intravitreal bevacizumab to treat choroidal neovascular membranes (CNVMs). Retina 28:910; author reply 910-911. doi:10. 1097/IAE.0b013e31816d81d0

31. Finger RP, Charbel Issa P, Schmitz-Valckenberg S, Holz FG, Scholl HN (2011) Long-term effectiveness of intravitreal bevacizumab for choroidal neovascularization secondary to angioid streaks in pseudoxanthoma elasticum. Retina 31:1268-1278. doi:10.1097/ IAE.0b013e318207d1dc

32. Savastano MC, Minnella AM, Zinzanella G, Falsini B, Caporossi A (2014) Successful long-term management of choroidal neovascularization secondary to angioid streaks in a patient with pseudoxanthoma elasticum: a case report. J Med Case Rep 8:458. doi:10.1186/1752-1947-8-458

33. Zebardast N, Adelman RA (2012) Intravitreal ranibizumab for treatment of choroidal neovascularization secondary to angioid streaks in pseudoxanthoma elasticum: five-year follow-up. Semin Ophthalmol 27:61-64. doi:10.3109/08820538.2012.680644

34. Rinaldi M, Dell'Omo R, Romano MR, Chiosi F, Cipollone U, Costagliola $C$ (2007) Intravitreal bevacizumab for choroidal neovascularization secondary to angioid streaks. Arch Ophthalmol 125:1422-1423. doi:10.1001/archopht.125.10.1422

35. Orly Gal-Or CB, Bailey Freund K (2015) Optical coherence tomography angiography findings of choroidal neovascularization in pseudoxanthoma elasticum. Int J Retin Vitr 1:11

36. Abraham P, Yue H, Wilson L (2010) Randomized, double-masked, sham-controlled trial of ranibizumab for neovascular age-related macular degeneration: PIER study year 2. Am J Ophthalmol 150: 315-324 e311. doi:10.1016/j.ajo.2010.04.011

37. Boyer DS, Heier JS, Brown DM, Francom SF, Ianchulev T, Rubio RG (2009) A phase IIIb study to evaluate the safety of ranibizumab in subjects with neovascular age-related macular degeneration. Ophthalmology 116:1731-1739. doi:10.1016/j.ophtha.2009.05.024

38. Lalwani GA, Rosenfeld PJ, Fung AE, Dubovy SR, Michels S, Feuer W, Davis JL, Flynn HW Jr, Esquiabro M (2009) A variable-dosing regimen with intravitreal ranibizumab for neovascular age-related macular degeneration: year 2 of the PrONTO study. Am J Ophthalmol 148:43-58 e41. doi:10.1016/j. ajo.2009.01.024 